\title{
Bridging theory and bow hunting: human cognitive evolution and archaeology
}

\author{
Frederick L. Coolidge ${ }^{1}$, Miriam Noël Haidle ${ }^{2}$, Marlize Lombard ${ }^{3,4, *}$ \\ \& Thomas Wynn ${ }^{5}$
}

\section{Introduction}

Recognising elements of a 'modern' mind or complex cognition in Stone Age archaeology is difficult and often disputed. A key question is whether, and in what way, the thinking of Homo sapiens differs from that of other species/sub-species of hominins. We argue that if the question of whether the modern mind is different from that of our ancestors or other members of the hominin family is to be fully explored, some focus should fall on technologies and behaviours unique to $H$. sapiens. Here we hypothesise about one such techno-behaviour: bow hunting (Figure 1). Other technologies and their associated behavioural repertoires, such as the heat treatment of rocks to improve knapping properties, and hunting with snares, represent similar opportunities to explore the cognition of early H. sapiens (Wadley 2010, 2013).

\section{Archaeology of bow hunting, bridging theory and cognitive interpretation}

Archaeological evidence for bow hunting is thus far exclusive to $H$. sapiens (Shea \& Sisk 2010; Williams et al. 2014), having never been found in association with other members of the Homo genus. Bow hunting was long thought of as a recent Holocene invention, but new evidence from southern Africa is pushing the earliest date of this technological innovation back to between 37000 and 65000 years ago (Backwell et al. 2008; Lombard \& Phillipson 2010; d'Errico et al. 2012; Robbins et al. 2012), perhaps even as far back as 71000 years ago (McBrearty 2012). We know that this techno-behaviour is associated exclusively with H. sapiens in the context of southern Africa as human populations in the region are known

1 Psychology Department, University of Colorado, 1420 Austin Bluffs Parkway, Colorado Springs, CO 80918, USA

2 The Role of Culture in Early Expansions of Humans Research Center, Heidelberg Academy of Sciences and Humanities, Senckenberg Research Institute, Senckenberganlage 25, D-60325 Frankfurt am Main, Germany

3 Department of Anthropology and Development Studies, University of Johannesburg, PO Box 524, Auckland Park Campus, Johannesburg 2006, South Africa (Email: mlombard@uj.ac.za)

4 Stellenbosch Institute for Advanced Study, Wallenberg Research Centre at Stellenbosch University, Marais Street, Stellenbosch 7600, South Africa

5 Department of Anthropology, University of Colorado, 1420 Austin Bluffs Parkway, Colorado Springs, CO 80918, USA

* Author for correspondence 


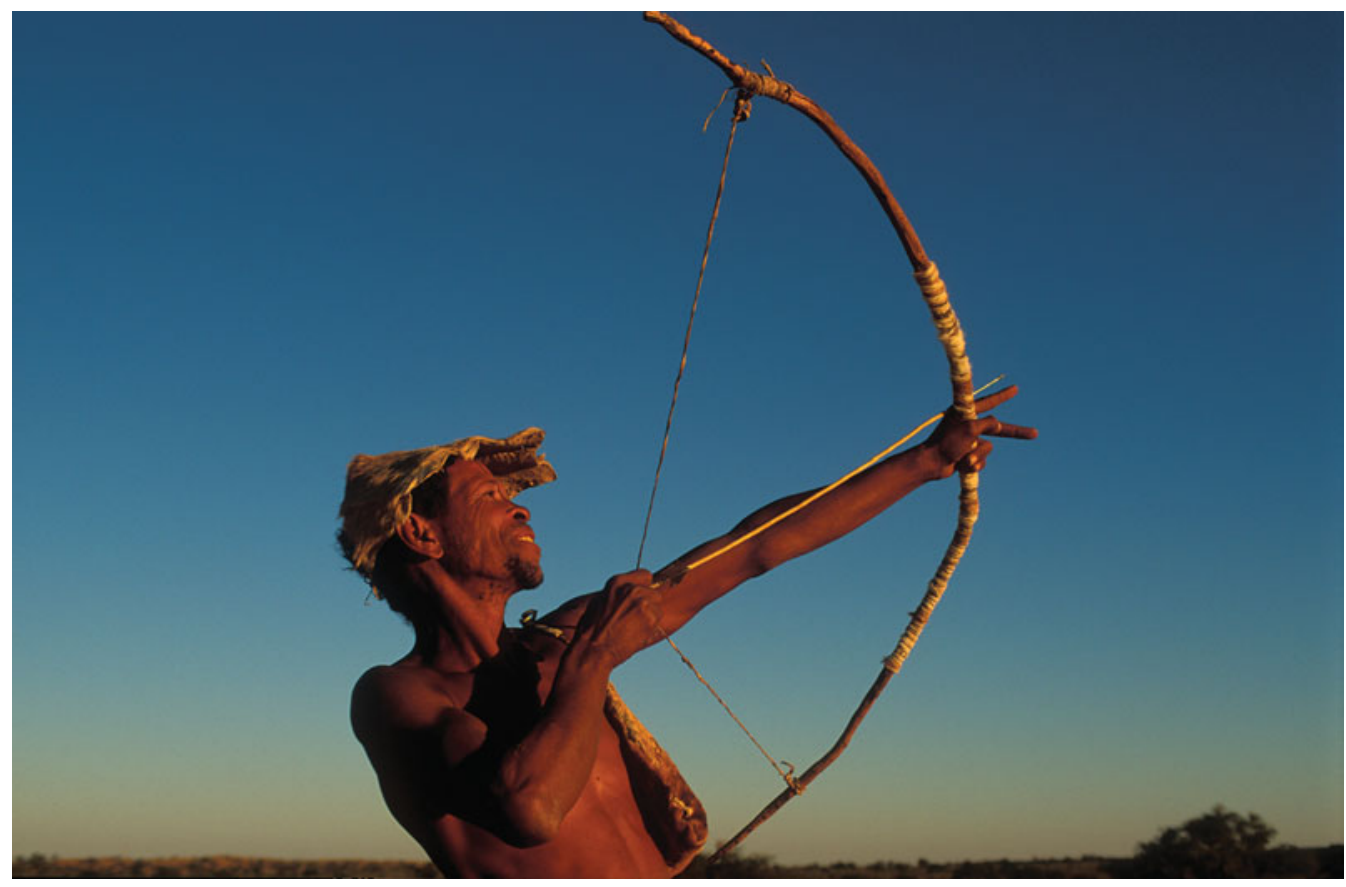

Figure 1. San individual hunting with bow and arrow, Kalahari, Northern Cape, South Africa (photograph used with permission from Ariadne van Zandbergen (C) The Africa Image Library).

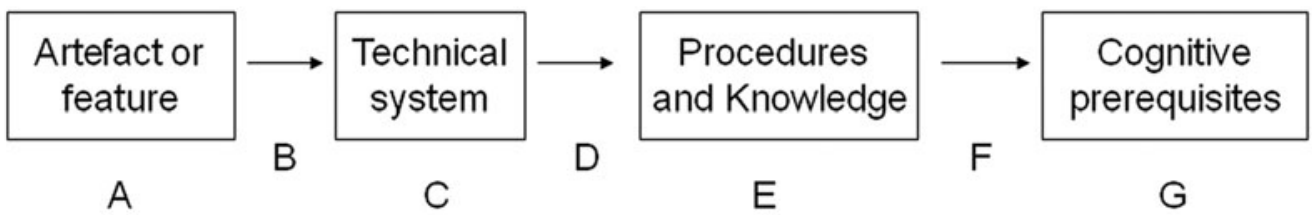

Figure 2. Bridging arguments for archaeological assessment of prehistoric cognition.

to have been anatomically modern since at least 100000 years ago (Dusseldorp et al. 2013), and because features of the DNA profile of populations currently living in the region can also be traced back to at least 100000 years ago (see Lombard et al. 2013 for cross-disciplinary overview). The antiquity of these recent finds indicates that bow-and-arrow technology could be relevant for investigating cognitive evolution.

Archaeological assessments of prehistoric cognition must rest on a series of bridging arguments (Wynn 2009; Botha 2010; Wadley 2013; Haidle 2014) (Figure 2). In the case of bow hunting, archaeological data (A) consist mostly of stone and bone tools. The technical system $(\mathrm{C})$ is inferred using artefact attributes and functional interpretations. Inferring the technical system from the archaeological evidence requires an explicit justification or, in Botha's terms, it requires that the argument be warranted (Botha 2010). Here, the case rests on Southern African ethnographic evidence of microliths used as arrow tips, and the temporal extension of this evidence into Later Stone Age assemblages, including actual (C) Antiquity Publications Ltd, 2016 
stone-tipped arrows (Binneman 1994). This link in the inference chain is uncontroversial and accepted by virtually all archaeologists of the South African Stone Age. A detailed reconstruction and analysis of perceptions and actions in the problem-solution sequences of the manufacture and use of a bow-and-arrow set (Figure 3) (Lombard \& Haidle 2012) addresses the next bridging argument (C-D-E) (Figure 2). These sequences describe how the activities were organised and what artisans had to know, conceive and do to accomplish their goals (see Haidle 2014 for a more detailed discussion of cognigrams and effective chains in relation to bridging arguments).

The final bridge in a cognitive interpretation is an argument for the cognitive systems underpinning the different reconstructed activities. Many self-described cognitive interpretations skip this step, assuming that the number of elements and steps in a problem-solution sequence is somehow a direct measure of cognition. We emphasise that technical complexity may be the result of a variety of cognitive processes, the probability and plausibility of which should be discussed in the interpretative process. Although interdependent with cognitive performances, technical complexity is part of a behavioural pattern and cannot be a direct measure of anything cognitive. To argue about cognition it is necessary to introduce knowledge of cognitive systems. Thus, the final bridging argument (E-F-G) (Figure 2) must be built by linking archaeological features to explicit hypotheses of cognition (Garofoli \& Haidle 2014). The strength of the final inference rests on the power of the cognitive hypotheses employed and the success in linking the observations drawn from the archaeological data to components of the hypothesis. Strict parsimony must apply. The simplest cognitive system that can account for archaeological features must be given priority.

\section{Expert cognition and bow-and-arrow technology}

Teasing bow-and-arrow technology apart demonstrates elaborate craft production, equivalent in its basic organisation to current craft production, such as blacksmithing (Keller \& Keller 1996). Primary among these similarities is the overarching hierarchical outline of the task. There was clearly a large-scale goal and plan-the functioning systemthat can be broken down into a number of more or less self-contained technical units or modules (Lombard \& Haidle 2012). The cognitive requirements for the modules are rather different from those required to coordinate the entire task, and it is appropriate to treat them separately. Execution of the individual modules relies primarily on the resources of expert cognition (Ericsson \& Kintsch 1995; Ericsson \& Delaney 1999). An expert performance has several attributes that distinguishes it from other activities:

1. Rapid problem assessment.

2. Rapid switching to alternative solutions when required.

3. Almost error-free execution.

4. Attention switching to other tasks without loss of information.

5. Restriction to a narrow range of expertise.

6. Years of practice to acquire mastery. 
Frederick L. Coolidge et al.

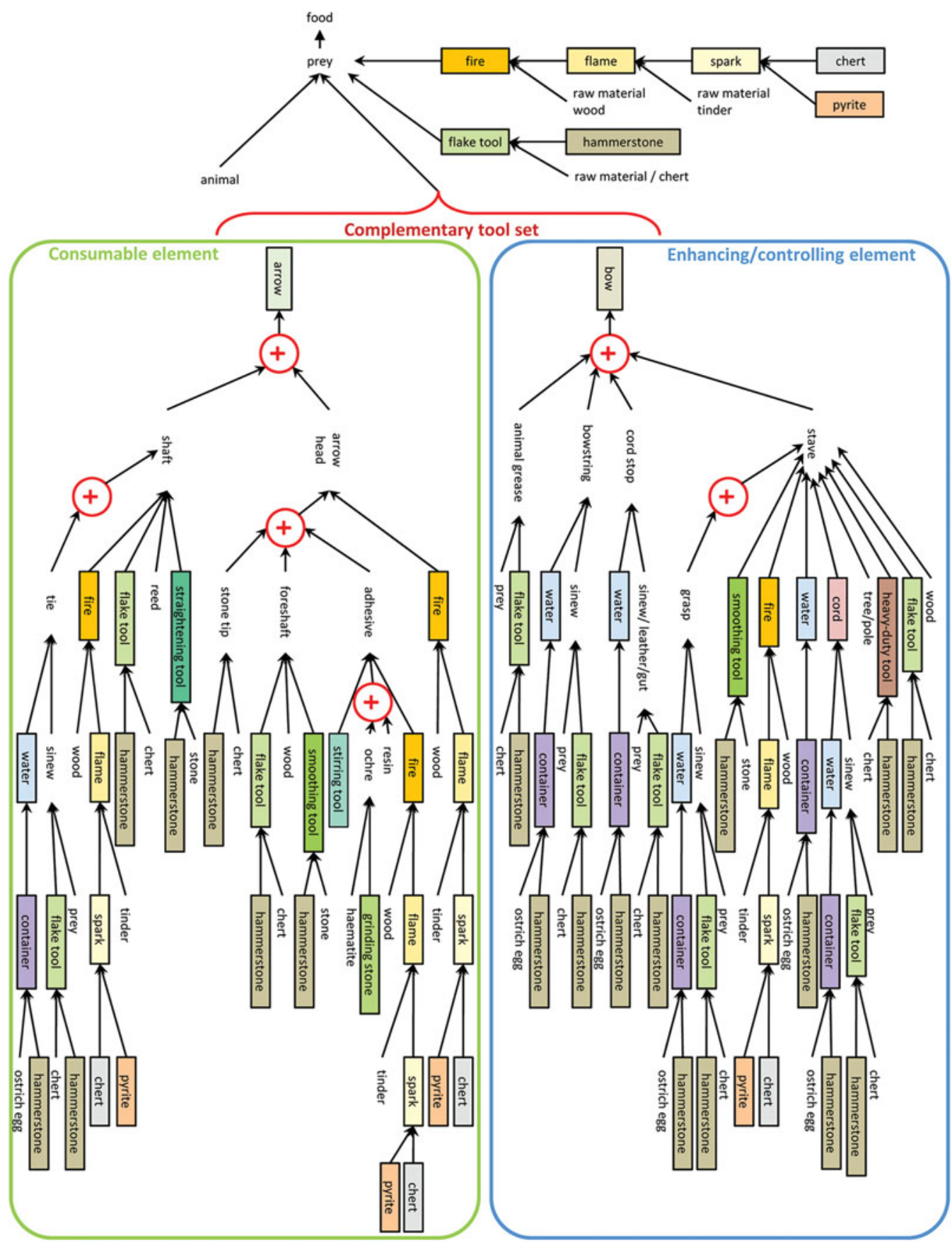

Figure 3. Hypothetical, effective chain of foci in the action sequence of manufacture and use of a bow and stone-tipped arrow set, with the effects the foci have on each other, reconstructed from experimental, archaeological and ethnographic information (adapted from Lombard \& Haidle 2012).

C) Antiquity Publications Ltd, 2016 
Expertise operates in domains such as chess, sport, musical performance and medical diagnosis (Ericsson \& Delaney 1999), but is also at play in technical activities (Wynn \& Coolidge 2004, 2010). An essential component to all expert performance is practice. Practice is essential because expertise relies on well-learned sequences of knowledge and action, constructed using two cognitive short cuts-chunking and chaining. Chunking involves dividing bodies of information, or actions into smaller, more easily processed chunks. Chunks are then chained together into longer sequences by repetition; often a final element in one chunk acts as a cue for the initial element in the next. This organisation is true for both verbal and procedural information and is most familiar in the motor routines of sport and instrumental music performance. Chunking and chaining must be learned by repetition.

This cognitive system is difficult to access via conscious attention, and the chunks and cues cannot be learned by volition, but expertise is not exclusively a domain of chunking and chaining and procedural cognition. Working memory (WM) plays a role, as most clearly described in the model of long-term working memory (LTWM) (Ericsson \& Delaney 1999). Again, cues are key in the functioning of this model. The expert acquires a long chain of information through practice, and then attaches a kind of access button to it-a cue. When he or she retrieves the cue into WM it instantly accesses all the information to which it has been linked (e.g. a chess opening such as the Sicilian Defence). One of the essential tasks in acquiring expert ability is assembling clusters of cues, referred to as a retrieval structure (Ericsson \& Delaney 1999). An expert learns a huge number of retrieval structures, tied to almost every conceivable variation in the task condition. As a form of cognition, expertise is almost certainly old in an evolutionary sense. Chunking and chaining are old learning mechanisms, as is cueing. The extent of expert knowledge is limited primarily by the size of long-term memory. WM capacity is relevant only in the number of retrieval structures one can access at once, or, probably, and more importantly for our current topic, the amount of free attention space available in WM after a retrieval structure has been activated.

Each of the technical modules of the bow and arrow could easily be learned via expert cognition. Within each phase, the steps are chunks of procedure chained together, and the shifts in attention are similarly organised into a sequence, one cueing the next. Even the phases themselves can be executed in this successive manner (Gatewood 1985). Flexibility is built into the procedure. There are, for instance, at least four alternative ways to bend the stave (Lombard \& Haidle 2012). Variation in local conditions and personal history cue the appropriate sequence of actions. The more staves the artisan produces, the more automatic the cognitive retrieval structure becomes. Consequently, decisions require increasingly less attention, resulting in a diminished occupation of WM capacity. Producing a bow stave is a classic example of expert cognition at work. Even during the application of learned modules, when the stave is fitted with a string to produce a composite tool, the bow falls easily within the domain of expertise.

This kind of thinking is not a recent evolutionary acquisition. It was well within the cognitive range of Neanderthals and all early forms of $H$. sapiens. Elements of chunking and chaining, and thus expertise, can be traced back to early stone tool production at least 3.3 million years ago (Harmand et al. 2015). It is probable that an increase in LTWM capacity accompanied the transition from Homo erectus to Homo heidelbergensis (this would 
be consistent with an increase in brain size), but basic expert cognition would appear to have evolved much earlier. We suspect that even $H$. heidelbergensis could have learned to execute most, if not all, of the isolated modules associated with producing a bow and arrow, but we also aver that they probably could not have invented a bow and arrow, and almost certainly could not have conceived of, and organised, the entire system. For this, something more than expertise is required.

\section{Episodic memory and bow hunting}

It is impossible to detect how bow-and-arrow technology was first invented. The principle of parsimony requires that we assume the simplest form of innovation was in play. In technology this involves fortuitous mistakes or attentive minor modifications of known procedures. Both rely on free attention space in WM-i.e. someone needed to 'notice' the fortuitous mistake or alternative step (Wynn \& Coolidge in press). There is no reason to deny this ability in early $H$. sapiens, neanderthalensis or heidelbergensis. The bow and arrow required many innovations, and they may have occurred over a shorter time span than innovations in stone-tipped spears, suggesting that more people had excess WM capacity, or that there was a greater individual excess of WM capacity. There is, however, something about the bow-and-arrow system as a whole that implies an important development in cognitionthe manufacturing process requires a much longer temporal extension of activity, stretching the consideration of forthcoming conditions much further into the future. The evidence here comes not from the technical modules themselves, but from the overarching plan of a complementary set of different composite tools, as summarised in the effective chain of thought and action (Figure 3).

To produce and operate an effective bow-and-arrow system, one must be able to access the entire system in attention, at least occasionally. Both elements, the bow and the arrow, not only require adjustment relative to the final goal, but must also be conceived relative to one another. When an arrow is made, it is not only the peculiarities of the envisaged prey that are taken into account, but also the specificity of the bow as a technological complement. Without this, one could not plan the acquisition of the disparate elements necessary for the different modules, or ensure that the required materials were available. The best means of achieving this is to place oneself in an imagined future state and evaluate the imagined future situation. Expertise alone cannot do this. It does not account for the reactivation of all the modules over temporal and spatial gaps. A more specific cognitive model for the understanding of this scale of the technology is that of episodic memory. We propose that episodic memory is directly linked to bow-and-arrow use, and may be considered a necessary but not independently sufficient condition.

Episodic memory allows for the recollection of past experiences (Tulving 2002; Tulving $\&$ Kim 2007). When people recall a past event, they mentally travel back in time, but are aware that the conscious re-experience of the event is qualitatively different from the initial experience. Thus, episodic memory involves the recollection of events and other elements associated with those events (event clusters), involving a special kind of awareness of the fact that if events can be re-imagined, and even modified (consciously or unconsciously), then time itself is subjective. The consciousness of one's self in a past memory, or one's conscious

(C) Antiquity Publications Ltd, 2016 
manipulation of a past memory, is what Tulving referred to as autonoetic awareness. Tulving further hypothesised that episodic memory was a recently evolved phenomenon and one that is probably unique to H. sapiens (Tulving 2002; Tulving \& Kim 2007).

Humans do share this kind of memory with most animals, but at some point in recent human evolution, true episodic memory evolved and hominins became unique. Earlier hominins were probably capable of acquiring and using these past events (i.e. knowledge). Tulving (2002) proposed that they could solve problems in the present based on past experiences, but that they were probably unaware that they were doing so. Here, we might elaborate upon our reference to 'true' episodic memory. Although the terms 'episodic memory' and 'autobiographical memory' are often used interchangeably, we would propose that autobiographical memory is a subset of the broader category of episodic memory, the latter certainly characteristic of many animal species (e.g. Allen \& Fortin 2013). Autobiographical memory, however, involves a clear sense of one's self in the event's recollection; it may be unique to $H$. sapiens and recently evolved.

Episodic memory is not reproductive but it is constructive, and it is therefore subject to all kinds of errors and illusions (Schacter 1999). It may well be that these imperfections of the episodic memory system led to the 'fortuitous' mistakes we referred to earlier in the simplest forms of innovation. Numerous examples of these inaccuracies may be found in literature, including the well-documented vagaries of eye-witness testimony and confabulations, where people intentionally or unintentionally mix the past with both fact and fiction, often without a complete awareness of doing so. Thus, it has long been noted that episodic memory is 'fundamentally constructive, rather than reproductive' (Schacter 1999; Addis et al. 2007; Schacter \& Addis 2007; Addis et al. 2009). Consequently, Schacter and Addis (2007) proposed a constructive episodic simulation hypothesis, which allows for the recombination of past details or events imagined in the future into novel configurations. These simulations can recall past events in a highly flexible manner in order to enhance the success of immediate or distant future actions.

Schacter and Addis (2007) reasoned that, as the future is not an exact representation of the past, the ability to simulate future events must be inherently flexible in order to recall, extract and recombine aspects of past events to ensure the success of future actions. Their concept of constructive episodic simulation may represent the critical cognitive component for bow-and-arrow technology as well as its 'inexact' nature, which we referred to earlier. Their concept supports our key bridging argument for the nature of a cognitive system as a whole, which can activate, deactivate and reactivate expertise modules over temporal and spatial distances.

\section{Tentatively bridging cognitive and neural spheres}

It has been proposed that a sense of self and self-representation may have its neurological foundations in the superior medial parietal lobes, i.e. the precuneus (Lou et al. 2004). Again, it may be no mere coincidence that episodic memory has also been linked to the precuneus, as well as prefrontal and medial temporal regions (e.g. Schacter \& Addis 2007; Schacter et al. 2007). We have already intimated that this relationship between recalling the past, simulating the future, and one's sense of self (which may or may not be a necessary requisite), 
may rest upon similar neuronal substrates (e.g. Okuda et al. 2003), particularly the precuneus (Addis et al. 2007, Buckner \& Carroll 2007; Spreng \& Grady 2010). Provocatively, Bruner (2004, 2010) has recently found evidence for precuneal expansion in recent $H$. sapiens not shared by Neanderthals.

\section{Conclusion}

It appears that the cognitive requirements for bow-and-arrow technology, or, as for snares, those that are operated "out of sight, but not out of mind" (Wadley 2010: 188), may have required a fully modern episodic memory system: a cognitive system that is capable not only of autobiographical memory retrieval, but also of constructive episodic memory simulations. If the latter suppositions find further support, then the early makers of bow-and-arrow technologies in all likelihood possessed a fully autonoetic awareness. This conclusion may also be bolstered by a recent finding that, in an event-queuing paradigm, it is unlikely that future prospection relies solely upon autobiographical/episodic memory networks (D’Argembeau \& Demblon 2012). D'Argembeau and Demblon argue that their findings strongly suggest that personal goals, which rely upon personal abstract knowledge, provide an important framework for the overall organisation of imagined events. Thus, the imagination of future events "may be linked together in broader event sequences on the basis of their causal roles in achieving personal goals" (Tulving 2002: 16). Finding evidence for a sense of self in the archaeological record is a Herculean task. Recent work (D'Argembeau \& Mathy 2011; D'Argembeau \& Demblon 2012) that demonstrates that a personal sense of self and awareness of one's goals is critical to linking and organising successful future simulations, may provide a tenuous basis for a near modern or fully modern sense of self and autonoetic thinking_-possibly earlier than 60000 years ago.

\section{Acknowledgements}

We thank two reviewers and the editor for thoughtful comments that helped to improve this paper.

\section{References}

Addis, D., A. Wong \& D. Schacter. 2007.

Remembering the past and imagining the future: common and distinct neural substrates during event construction and elaboration. Neuropsychologia 45: 1363-77. ttp://dx.doi.org/10.1016/ j.neuropsychologia.2006.10.016

Addis, D., L. PAN, M.A. Vu, N. LAISER \& D. SCHACTER. 2009. Constructive episodic simulation of the future and the past: distinct subsystems of a core brain network mediate imagining and remembering. Neuropsychologia 47: 2222-38. http://dx.doi.org/10.1016/ j.neuropsychologia.2008.10.026

Allen, T.A. \& N.J. ForTin. 2013. The evolution of episodic memory. Proceedings of the National Academy of Sciences of the USA 110 (Supplement 2): 10379-86.

http://dx.doi.org/10.1073/pnas.1301199110

(C) Antiquity Publications Ltd, 2016
BACKWEll, L., F. D’ERrico \& L. WADLEY. 2008. Middle Stone Age bone tools from the Howiesons Poort layers, Sibudu Cave, South Africa. Journal of Archaeological Science 35: 1566-80.

http://dx.doi.org/10.1016/j.jas.2007.11.006

Binneman, J.N.F. 1994. A unique stone-tipped arrowhead from Adam's Kranz Cave, Eastern Cape. Southern African Field Archaeology 3: 58-60.

BотHA, R. 2010. On the soundness of inferring modern language from symbolic behaviour. Cambridge Archaeological Journal 20: 345-56. http://dx.doi.org/10.1017/S0959774310000454

BRUNER, E. 2004. Geometric morphometrics and paleoneurology: brain shape evolution in the genus Homo. Journal of Human Evolution 47: 279-303. http://dx.doi.org/10.1016/j.jhevol.2004.03.009

- 2010. Morphological differences in the parietal lobes with the human genus: a neurofunctional perspective. Current Anthropology 51: S77-88. http://dx.doi.org/10.1086/650729 


\section{Bridging theory and bow hunting: human cognitive evolution and archaeology}

BuCKNER, R.L. \& D.C. CARroll. 2007. Self-projection and the brain. Trends in Cognitive Science 11: 49-57. http://dx.doi.org/10.1016/j.tics.2006.11.004

D’Argembeau, A. \& J. Demblon. 2012. On the representational systems underlying prospection: evidence from the event-cueing paradigm. Cognition 125: 160-67. http://dx.doi.org/10.1016/j.cognition.2012.07.008

D’Argembeau, A. \& A. Mathy. 2011. Tracking the construction of episodic future thoughts. Journal of Experimental Psychology: General 140: 258-71. http://dx.doi.org/10.1037/a0022581

D’Errico, F., L. Backwell, P. Villa, I. Degano, J. LuCEJKO, M. BAMFORD, T.F.G. Higham, M. Colombini \& P.B. Beaumont. 2012. Early evidence of San material culture represented by organic artefacts from Border Cave, South Africa. Proceedings of the National Academy of Sciences of the USA 109: 13214-19. http://dx.doi.org/10.1073/pnas.1204213109

Dusseldorp, G., M. Lombard \& S. Wurz. 2013. Pleistocene Homo and the updated Stone Age sequence of South Africa. South African Journal of Science 109(5/6): 46-52. http://dx.doi.org/10.1590/sajs.2013/20120042

ERICSSON, K. \& P. DeLANEY. 1999. Long-term working memory as an alternative to capacity models of working memory in everyday skilled performance, in A. Miyake \& P. Shah (ed.) Models of working memory: mechanisms of active maintenance and executive control: 257-97. Cambridge: Cambridge University Press. http://dx.doi.org/10.1017/ CBO9781139174909.011

ERICSSON, K.A. \& W. KINTSCH. 1995. Long-term working memory. Psychology Review 102: 211-45. http://dx.doi.org/10.1037/0033-295X.102.2.211

Garofoli, D. \& M.N. Haidle. 2014. Epistemological problems in cognitive archaeology: an antirelativistic proposal towards methodological uniformity. Journal of Anthropological Sciences 92: 7-41.

GATEWOOD, J. 1985. Actions speak louder than words, in J. Dougherty (ed.) Directions in cognitive anthropology: 199-220. Urbana: University of Illinois Press.

HAIDLE, M.N. 2014. Building a bridge-an archaeologist's perspective on the evolution of causal cognition. Frontiers in Psychology 5: 1-15. http://dx.doi.org/10.3389/fpsyg.2014.01472

Harmand, S., J.E. LeWIS, C.S. Feibel, C.J. Lepre, S. Prat, A. Lenoble, X. Boës, R.L. Quinn, M. Brenet, A. Arroyo, N. Taylor, S. Clément, G. DaVER, J.-P. Brigal, L. LEAKEy, R.A. MORTLOCK, J.D. WRIGHT, S. LOKORODI, C. Kirwa, D.V. Kent \& H. Roche. 2015. 3.3-million-year-old stone tools from Lomekwi 3, West Turkana, Kenya. Nature 521: 310-15. http://dx.doi.org/10.1038/nature14464
Keller, C. \& J. Keller. 1996. Cognition and tool use: the blacksmith at work. Cambridge: Cambridge University Press.

Lombard, M. \& M.N. Haidle. 2012. Thinking a bow-and-arrow set: cognitive implications of Middle Stone Age bow and stone-tipped arrow technology. Cambridge Archaeological Journal 22: 237-64. http://dx.doi.org/10.1017/S095977431200025X

LOMbard, M. \& L. PHILlipson. 2010. Indications of bow and stone-tipped arrow use 64000 years ago in KwaZulu-Natal, South Africa. Antiquity 84: 635-48. http://dx.doi.org/10.1017/S0003598'00100134

Lombard, M., L. Phillipson, C. Schlebusch \& H. SoOdyall. 2013. Bridging disciplines to better elucidate the evolution of early Homo sapiens in southern Africa. South African Journal of Science 109: 27-34. http://dx.doi.org/10.1590/sajs.2013/20130065

Lou, H.C., B. Luber, M. Crupain, J.P. KeEnan, M. NOWAK, T.W. KJAER, H.A. SACKEIM \& S.H. LISANBY. 2004. Parietal cortex and representation of the mental self. Proceedings of the National Academy of Sciences of the USA 101: 6827-32. http://dx.doi.org/10.1073/pnas.0400049101

MCBREARTY, S. 2012. Sharpening the mind. Nature 491: 531-32. http://dx.doi.org/10.1038/nature11751

OKuda, J., T. Fuji, H. OHTAKe, T. Tsukiura, K. Tanji, K. Suzuki, R. KaWashima, H. Fukuda, M. ITOH \& A. YAMAdORI. 2003. Thinking of the future and past: the roles of the frontal pole and the temporal lobes. Neuroimage 19: 1369-80. http://dx.doi.org/10.1016/S1053-8119(03)00179-4

Robbins, L.H., A.C. CAmpbell, G.A. BrooK, M.L. MurPhy \& R.K. HitchCOCK. 2012. The antiquity of the bow and arrow in the Kalahari Desert: bone points from White Paintings Rockshelter, Botswana. Journal of African Archaeology 10: 7-20. http://dx.doi.org/10.3213/2191-5784-10211

SCHACTER, D. 1999. The seven sins of memory: insights from psychology and cognitive neuroscience. American Psychology 54: 182-203. http://dx.doi.org/10.1037/0003-066X.54.3.182

SCHACTER, D. \& D. AdDIS. 2007. The cognitive neuroscience of constructive memory: remembering the past and imagining the future. Philosophical Transactions of the Royal Society B 362: 773-86. http://dx.doi.org/10.1098/rstb.2007.2087

SCHACTER, D., D.R. AdDIS \& R.L. BUCKNER. 2007. Remembering the past to imagine the future: the prospective brain. Nature Reviews Neuroscience 8: 657-61. http://dx.doi.org/10.1038/nrn2213

(C) Antiquity Publications Ltd, 2016 
SHEA, J.J. \& M.L. SISK. 2010. Complex projectile technology and Homo sapiens dispersal into Western Eurasia. PaleoAnthropology 2010: 100-22.

Spreng, R.N. \& C.L. Grady. 2010. Patterns of brain activity supporting autobiographical memory, prospection, and theory of mind, and their relationship to the default mode network. Journal of Cognitive Neuroscience 22: 1112-23. http://dx.doi.org/10.1162/jocn.2009.21282

Tulving, E. 2002. Episodic memory: from mind to brain. Annual Review of Psychology 53: 1-25. http://dx.doi.org/10.1146/ annurev.psych.53.100901.135114

Tulving, E. \& A. KIM. 2007. The evolution of foresight: what is mental time travel, and is it unique to humans? Behavioral and Brain Sciences 30: 334-35.

WADLEY, L. 2010. Were snares used in the Middle Stone Age and does it matter? A review and case study from Sibudu, South Africa. Journal of Human Evolution 58: 179-92.

http://dx.doi.org/10.1016/j.jhevol.2009.10.004
- 2013. Recognizing complex cognition through innovative technology in Stone Age and Palaeolithic sites. Cambridge Archaeological Journal 23: 163-83. http://dx.doi.org/10.1017/S0959774313000309

Williams, V.M.E., A. Burke \& M. LOMBARD. 2014. Throwing spears and shooting arrows: preliminary results of a pilot neuroarchaeological study. South African Archaeological Bulletin 69: 199-207.

WynN, T. 2009. Hafted spears and the archaeology of mind. Proceedings of the National Academy of Sciences of the USA 106: 9544-45. http://dx.doi.org/10.1073/pnas.0904369106

WynN, T. \& F.L. CoOLIDGE. 2004. The expert Neandertal mind. Journal of Human Evolution 46: 467-87. http://dx.doi.org/10.1016/j.jhevol.2004.01.005

- 2010. How Levallois reduction is similar to, and not similar to, playing chess, in A. Nowell \& I. Davidson (ed.) Stone tools and the evolution of human cognition: 83-104. Boulder: University of Colorado Press.

- In press. Technical cognition, working memory, and creativity. Pragmatics \& Cognition.

Received: 20 August 2014; Accepted: 19 November 2014; Revised: 26 January 2015

(C) Antiquity Publications Ltd, 2016 